\title{
“THE POET'S VOICE”: DIALOGICITY AND CULTURAL REGENERATION IN FAULKNER'S ABSALOM, ABSALOM!
}

\begin{abstract}
Faulkner's oeuvre took shape in and through his continual, conflictive interaction with Southern culture and heritage. This article argues that Faulkner's works are conceived as correctives to the shortcomings of his cultural environment. Through a close reading of Absalom, Absalom!, a conception of unconstrained communication and diversity comparable to Bakhtin's 'dialogicity' is identified as the node at which culture and text interconnect on several levels. In a first step, the article outlines the three levels of dialogic communication - linguistic, discursive, and epistemological - at work in Faulkner's oeuvre. In a second step, it draws on functional models of literature from the areas of narratology and cultural ecology to analyze how dialogicity is inscribed into the very structure of Absalom, Absa$l o m$ ! to make it a regenerative contribution to Southern public discourse.
\end{abstract}

If there is one central aspect of Faulkner's oeuvre, a theme that pervades all of his works and lies at the heart of both their technical novelty and enduring impact on readers worldwide, it is the theme of individuality. All of Faulkner's works revolve around individuals struggling to define their identity and to create a space in which this identity will be respected. In his famous Nobel Prize speech, Faulkner affirmed that "the problems of the human heart in conflict with itself ... alone can make good writing because only that is worth writing about" and pointed out that writing about individuality has not only a literary but also a cultural function:

I believe that man will not merely endure: he will prevail. He is immortal, not because he alone among creatures has an inexhaustible voice, but because he has a soul, a spirit capable of compassion and sacrifice and endurance. The poet's, the writer's, duty is to write about these things. ... The poet's voice need not merely be the record of man, it can be one of the props, the pillars to help him endure and prevail. (Faulkner 1967a, 723f.)

Literature, if well written, can connect to its cultural environment and act as a vitalizing force. In other words, that which distinguishes a truly literary text from any other text - its internal structure, its linguistic form - exerts some kind of epistemological influence on a culture. But this is not a oneway connection: the literary text is in turn shaped by the worldview that the writer has acquired from his cultural environment. Faulkner would have been the first to admit to that fact, as he struggled with the problems and contradictions of Southern culture all his life and acted out these struggles in his fiction, which reflects to an unusual degree his own cultural background. 
Throughout the nineteenth and twentieth centuries, the South had based its collective identity on a concept of individuality radically different from that of the North - and, by extension, from other Western societies - in that it opposed two of the most pervasive ideologemes of the age. On the one hand, it strove to preserve its quasi-aristocratic, patriarchal social system from the deracination and anonymization concomitant with industrial capitalism. On the other hand, it insisted on the separation between "blacks" and "whites" and on the inherent inferiority of the former, dismissing the central Enlightenment idea that "all men are created equal".

Faulkner was deeply immersed in the Southern way of life and always felt torn between its advantages and its shortcomings. He had been raised to hold in special regard antebellum traditions and codes of honor. In his younger years, his most influential role model was his great-grandfather, who had served as a Colonel in the Confederate Army. As a proud but critical Southerner, Faulkner frequently took a stand on the most controversial issues of his time, white supremacy and the segregation laws. The ambivalence of his position was widely noted. On the one hand, he defended his homeland and went so far as to say he would shoot every black man who took up arms to revolt against the political system of the South. On the other hand, he supported the emancipation of the black people and set impressive examples of black self-reliance and independence in his novels. Also, he criticized the segregated school system, which was unnecessarily expensive and resulted in "two identical systems neither of which are good enough for anybody" (Faulkner 1965, 93). Although his tendency to glorify the antebellum South, regardless of the egoism and ruthlessness of the white upper class, leaves him open to criticism, Faulkner's insistence on equality, even in the face of threats against his life and his family, shows his acceptance and support of his black compatriots' struggle for equal rights.

In this article, I will argue that Faulkner's literary works are constructed as correctives to the shortcomings of his cultural environment, with a view to disseminating a more viable, tolerant worldview. More specifically, I believe that his endeavor to help man endure and prevail revolves around an ideal of unconstrained communication similar to Mikhail Bakhtin's 'dialogicity', an ideal which is at work both within the text and beyond it. Faulkner's novels in particular are uttered not by one but by many voices; thus, diversity is inscribed into their very structure as a force at once linguistic, discursive, and epistemological. In a first step of my analysis, I will show how these three aspects of diversity as a principle of communication are combined in Bakhtin's concept of dialogicity. I will then draw on functional models of literature from the areas of narratology and cultural ecology to analyze how dialogicity is inscribed into the very structure of Absalom, Absalom!, Faulkner's exemplary and most ambitious attempt to come to terms with his cultural environment. 
Dialogicity is a cornerstone of Bakhtin's thought and, like so many of his central terms, is endowed with quite different meanings throughout his work. Gary Saul Morson and Caryl Emerson, in the standard English-language commentary on Bakhtin, distinguish three senses of the word "dialogue" which I call the epistemological, the discursive, and the linguistic sense. In its epistemological sense, Bakhtin thinks of dialogue as an entire mindset governing our communication, "a view of truth and the world" (Morson 1990, 131). Life, he claims, is a never-ending, "unfinalizable" process of communication between a multiplicity of embodied voices. As such, it is "by its very nature ... dialogic. To live means to participate in dialogue" (Bakhtin 1984, 293). Traditional epistemology has failed to take this fundamental aspect into account. It has therefore been confined to monologic truths, synthesized "summaries" that only allow for a single point of view. But it is possible, Bakhtin argues, "to imagine and postulate a unified truth that requires a plurality of consciousnesses, one that cannot be fitted into the bounds of a single consciousness" (Bakhtin 1984, 81). Such a conception of truth has obvious epistemological and political implications: in order to understand and represent reality adequately, every voice must be taken into account and individual points of view must not be suppressed by way of reduction, abstraction, or synthesis. Bakhtin speaks of a 'dialogic' conception of truth, and the very phrasing makes it clear that such an effort must be rooted in language.

In a second sense, dialogue is for Bakhtin a succession of speech acts, or 'utterances'. The utterance is by no means identical with linguistic units like 'sentence' or 'word'; it may consist of a short grunt or of an entire novel. It is formed by its context, that is, by the situation in which it is uttered - not by an autonomous speaker resorting to a neutral linguistic system, but by preceding and following (anticipated) utterances. Each of its features, from the linguistic rules used to form it to the worldview underlying it, has been acquired by its speaker in interaction with other people and other utterances. In this sense, the concept of dialogue is reminiscent of discourse as defined by Michel Foucault. Discourse is also made up of concrete speech acts whose formation is determined by previous speech acts to a larger extent than the speaker is aware. This is why I call this sense of dialogue the discursive sense. We have to keep in mind, however, that Bakhtin's inclusive definition of the utterance does not allow for an approach to dialogue as abstract as Foucault's theory of discourse. Moreover, Bakhtin's analysis of dialogue has another level to it that we do not find in Foucault, namely, a linguistic one.

To the 'macro-dialogue' of utterances corresponds a 'micro-dialogue' within every single word. The very words of which an utterance consists are already "populated" with connotations they have acquired in previous utterances (cf. Morson 1990, 137f.). In the discursive sense, all utterances are dialogic in that they are the constituents of dialogue. In the linguistic sense, however, there are different degrees of dialogicity, depending on how resistant the words (and their speakers) are against other voices. In everyday 
communication we want our utterances to express a specific content and nothing else, therefore we do not allow other voices into them - or if we do, these are "mediated" by our own, authoritative voice. Bakhtin speaks of "single-voiced words" (or "single-voiced discourse" - the Russian slovo comprises both these meanings) as opposed to "double-voiced words" that include our own voice as well as the unmediated voice of someone else. Examples of sustained double-voiced discourse include stylization, parody, and "the narration of a narrator when it functions as a compositional substitute for the author's word" (Bakhtin 1984, 190).

Since Bakhtin conceives dialogic epistemology as firmly rooted in language, it comes as no surprise that he turns to literature for instantiations of dialogicity. Literature, and in particular prose literature, is inherently dialogic to a greater degree than any other form of communication, since every "literary discourse more or less sharply senses its own listener, reader, critic, and reflects in itself their anticipated objections, evaluations, points of view" (Bakhtin 1984, 196). But it takes more than that to achieve true dialogicity. The inherent possibilities of language can only be brought to fruition when supplemented with a dialogic conception of truth. According to Bakhtin, it is in Dostoevsky that we find the first instantiation of this principle in literature. Dostoevsky overcame the "monologic" form of the novel by renouncing any final control over his characters and treating them as personalities in their own right. He constructed his novels not as unified utterances but as dialogues between utterances, a stage on which the free interplay of autonomous voices can take place. They constitute an entirely new form of prose literature which Bakhtin calls the 'polyphonic novel'. A polyphonic text combines the formal-linguistic, discursive, and epistemological aspects of dialogicity.

This, I think, is the reason why the concept is so illuminative when applied to Faulkner's novels. Man will endure and prevail, Faulkner says, because "he alone among creatures has an inexhaustible voice," and it is the poet's duty to record the voices of individuals and their "compassion and sacrifice and endurance". In other words, Faulkner believes that literature, if it represents as many authentic voices as possible, will make a discursive impact: it will instill in its readers respect for the voices of their fellow human beings, but also for their environment as a whole. This regenerative force, I believe, is inscribed into the very structure of Faulkner's texts, whose complexity reflects their commitment to dialogicity both as a worldview and as a principle of construction. In order to explain how these aspects connect how, in other words, a text can disseminate a dialogic worldview - I will briefly consider two functional models of literature.

Hubert Zapf's Literatur als kulturelle Ökologie, a recent study in ecocriticism, is based on the idea that "literature acts as an ecological principle or an ecological force within the larger system of its culture" (Zapf 2002, 3; my trans.). It differentiates three interrelated discursive functions of literature: one, the representation of the cultural system, especially the short- 
comings of its dominant discourses and power structures, in a 'culturalcritical metadiscourse'; two, the rectification of the excluded elements in an 'imaginative counterdiscourse'; three, the confrontation of the cultural system with the excluded elements in a 'reintegrative interdiscourse'. Even if this confrontation achieves no lasting improvement, Zapf argues, it has at least resulted in a moment of revitalization and has irreversibly undermined the authority of the dominant discourses. Thus, the discursive impact of literature is in principle regenerative.

In his case studies, Zapf locates the point of connection between textual structures and their cultural impact in the symbolic and metaphorical condensation of public discourse. Given that dialogicity is primarily a communicative phenomenon, however, I suggest to trace the discursive functions he defines - cultural-critical, imaginative, and reintegrative - in the narrative process. Gérard Genette, in what is arguably a standard model, distinguishes three levels of narration:

I propose ... to use the word story [histoire] for the signified or narrative content (even if this content turns out, in a given case, to be low in dramatic intensity or fullness of incident), to use the word narrative [récit] for the signifier, statement, discourse or narrative text itself, and to use the word narrating [narration] for the producing narrative action and, by extension, the whole of the real or fictional situation in which that action takes place. (Genette 1980,27)

It is feasible, I would argue, to establish a correspondence between the three levels of narration and the three discursive functions of literature defined by Zapf. The cultural-critical metadiscourse, in his model, relies on the histoire. Cultural criticism in literature is constituted neither by the idiosyncrasies of literary representation nor by its being narrated, but by the reader's direct response to the events and situations with which he is confronted. The imaginative counterdiscourse, on the other hand, is constituted in the récit, which takes these events and situations up and embeds them into a net of connotations in which they acquire a subversive force. As the conflicting aspects of the novel are confronted in the reintegrative interdiscourse, the story and its literary representation are made to interact in the narrative act, the narration. ${ }^{1}$ It is only on this more comprehensive level that the interplay of the antagonistic forces can be staged, and it is only here that a connection between the literary text and its discursive environment is possible. After all, a text has to be narrated in order to influence people.

Of course, reintegrative aspects can also be found in the histoire and in the récit. I am not suggesting that any of the discursive functions is confined to one level of the narrative process alone, but I do think that there are constitutive levels to each of the three functions. In other words, the way in

1 Note that I use the term narration for extradiegetic narration alone. Unlike Genette, I regard intradiegetic narration as part of the récit, since it does not transcend the frame of reference of the fictive world. 
which the literary text interacts with its discursive environment differs on each of the three levels of the narrative process. This will be the basic assumption of my discussion of Absalom as an exemplary dialogic text. First, I will identify the novel's story and the cultural criticism implied in the monologic worldview on which it is based. In a second step, I will analyze the different ways in which the story is told and the ways in which they contribute to the text's internal dialogicity. Finally, I will discuss the interplay of the different voices in the narrative act as an instance of interconnection between the text and its cultural environment.

\section{Cultural-Critical Metadiscourse: The Imperialist Character}

Absalom tells the story of Thomas Sutpen, a self-made man who rises from the ramshackle cabins of Tidewater Virginia to become a plantation owner in Jefferson, Mississippi. The formative incident of his life occurs in his early teens, when he is denied entrance through the front door of a planter's mansion because of his poverty. Shocked and outraged, young Sutpen tries to find a way of preventing such degradation in the future and resolves to reach a similar position of power: he will become a rich plantation owner and the patriarch of an honorable white family. The master narrative of Sutpen's story fuses the capitalist glorification of ruthless ascent ("from rags to riches") with an unflagging belief in the racist, feudal system of the Old South. It unites the dominant discourses of the North and the South to create a doubly egocentric value system which privileges the white self-made man at the top of the social pyramid. But Absalom is not the story of a successful planter. It is the story of a failure - the failure of Sutpen's "design" but also of the monologic worldview on which it is based. This worldview not only results in a distorted self-image but it creates enormous obstacles for meaningful social interaction.

Sutpen is what Hannah Arendt calls an "imperialist character": an adventurer who leaves his home to pursue his self-aggrandizement without having to respect the restraints of his social environment. In a way, Arendt suggests, young men of this disposition never grow up: the English colonialists she studied retained "a certain ... boyhood-noblesse which preserved and infantilized Western moral standards" (Arendt 1950, 307). And this is indeed the first obvious shortcoming of Sutpen's design: he develops it in his early teens with the help of childish, simplistic reasoning and not once in his life considers any modification; he even accepts separation from his homeland and his social environment to avoid any such modification. This double transformation of puerile longing - temporally, into the world of adults, and spatially, into a region devoid of social restrictions - recalls Arendt's analysis of the English imperialists. Sutpen's over-emphasis on selfaggrandizement and his disregard of counterbalancing influences render him obsessed with his design. When he returns from the war and sets to 
restoring his estate and dynasty, he is not concerned "that old age might have left him impotent to do what he intended to do, but that he might not have time to do it in before he would die. ... We did not know how he would go about it, nor I believe did he." The design has become an end in itself, an illogical obsession whose demands he fulfills with "electric furious immobile urgency" (Faulkner 1995, 160).

These traits form the basis on which he develops an "imperialist character". The term does not carry negative implications alone, and Sutpen is indeed self-reliant in the Emersonian sense of the word. He shares Emerson's conviction that "no kernel of nourishing corn can come to him but through his toil bestowed on that plot of ground which is given to him to till" (Emerson 1985, 176) and works hard to build his plantation "without asking or receiving help from any man" (Faulkner 1995, 272). But the selfcenteredness of such an attitude has a downside to it, and this downside is apparent as soon as Sutpen wants to start a family. He fails because he has never learned to regard others as personalities in their own right nor to set boundaries to his own ambition. From the beginning, his design does not consider limits of any kind; it reflects the totality of his experience at the planter's front door: "he was seeking among what little he had to call experience for something to measure it by, and he couldn't find anything" (Faulkner 1995, 233). He preserves this lack of measurement all his life, so that the (mono) logic of the design pervades all his thoughts and finally renders him unable to understand those who do not think in its terms. His lack of limits is reflected in the novel's allusions to the biblical Genesis myth, in which Sutpen assumes the role of God: in the beginning, he " $\mathrm{drag}[\mathrm{s}]$ house and formal gardens violently out of the soundless Nothing ... the Be Sutpen's Hundred like the oldentime Be Light" (Faulkner 1995, 8f.). On the sixth day man is created: six years after Sutpen's arrival, his son Henry is the first man to be born on the plantation (cf. Kartiganer 1964, 362). But Sutpen is not content with resting on the seventh day. His scheme goes beyond that of Genesis and includes the pursuit of his self-aggrandizement at the expense of those around him: on the eighth night, he "went out and subdued them" (Faulkner 1995, 254). The quotation refers to the eighth and last night of the slave revolt on the Haitian plantation, an incident paradigmatic in two ways. First, it shows Sutpen's ruthlessness: he spares neither himself nor others, a quality so striking that the Jefferson townspeople "look at him and say, Given the occasion and the need, this man can and will do anything" (Faulkner 1995, 46). Second, it expresses the hierarchy of Sutpen's world: his design is the universal norm and everyone else is subjected to it. $\mathrm{He}$ regards others as instruments that might be helpful in furthering his design and acknowledges their very existence only when they fit into this pattern.

The ruthless instrumentalization of others for his design, combined with an inability to understand their ways of thinking, ultimately causes Sutpen's downfall. His refusal to acknowledge Charles Bon turns out to be counterproductive: it confirms in Bon his desire to marry Judith and thus forces 
Henry to kill him and flee. When Sutpen turns to Rosa to father another male heir, his failure to recognize her sense of honor results in the mistake of making a dishonorable proposal which she cannot but reject. The full scope of his delusion, however, is revealed in his comment on the birth of Milly's child. The degrading comparison with his horse is received by her father, Wash Jones, in much the same way in which Sutpen received the scene at the Tidewater planter's front door. For both, a thoughtless rebuke marks the collapse of their entire worldview. Jones, for whom the faith in Sutpen's God-like grandeur and dignity as a representative of the Old South was the last certainty in an otherwise hostile world, cannot bear the disappointment and kills Sutpen in a rush of passion. The imperialist character has overreached and thus destroyed himself - without ever being aware of it.

\section{Imaginative Counterdiscourse: The NarRators}

In the summary I have given, Sutpen's story appears fairly coherent and straightforward. Readers of Absalom, however, are left with a very different impression. They find themselves confronted with six different narrators five characters and the extradiegetic third-person narrator - none of whom is entirely trustworthy: some are openly biased, some have never met Sutpen, some have a hidden agenda in telling his story, some are on the verge of insanity. But the mere fact that the novel is narrated not only by Sutpen but also by four other characters makes it impossible for his monologic story to prevail. As the following analysis will show, the multiplicity of new voices and perspectives thoroughly dialogizes the master narrative.

The first narrator is Sutpen himself, who tells General Compson about his childhood and his design - and it is the design that dominates his story, not only its content but also the motives he pursues in telling it the way he does. In fact, his autobiographical tale is itself a part of the design which demands that he enter into history as the founder of a long-lived dynasty, "to make that scratch, that undying mark on the blank face of the oblivion to which we are all doomed" (Faulkner 1995, 129). Therefore, it is important to him to not only make his intentions public and understandable to posterity, but to picture himself as a patriarchal founding-father whose sole motive was to ensure the success of his dynasty. "Thus what we get is really a double creation: the creation of Sutpen by Sutpen and the re-creation of this action and its consequences by the witnesses" (Bandry 1984, 87; my trans.). This is a tale whose narrator tries to control every single word in order to convey one specific, authoritative message. We have to keep in mind, though, that his is not the objective account against which all the others can be measured. On the contrary, Sutpen's desire to monologize his récit undermines its reliability. For example, he tends to downplay the difficulties and obstacles he encountered on his way to the top; for these, he simply substitutes the word "so". When he started working on the Haitian plantation he "realized 
that he would not only need courage and skill, he would have to learn to speak a new language ... So he learned the language" (Faulkner 1995, 248). Later, during the slave revolt, "the water gave out and something had to be done so he put the musket down and went out and subdued them. That was how he told it: he went out and subdued them ... Not how he did it" (Faulkner 1995, 254). Besides, he omits a significant part of his story because he cannot remember it - this, at least, is what he claims. This discontinuity undermines his control and creates "a vacuum into which the [other] narrators can take their places," allowing them to "speculate freely" whenever they find that a link or a whole part of the story is missing (Cullick 1996, 57). They gain independence from the master narrative and can engage in a more pluralized retelling.

Of the other narrators, the only one to have known Sutpen personally is Rosa Coldfield, his sister-in-law. Her life still is dominated by the incident that led to her flight from the plantation: Sutpen's proposal to marry her if she gave birth to a son first. Her education, which combines the Southern code of honor with conservative religious beliefs, has not only led her to reject his proposal but to condemn him whole-heartedly. She adheres to a dualistic logic of good and evil that casts Sutpen as a demon whose corruption, like original sin, will return to afflict his family. She does not seek for explanations at all but merely incorporates everything that happens into her dualistic pattern. Her description of Sutpen must remain one-sided and incomplete, since she perceives only his "evil" traits. Not surprisingly, her account of the story is narrow and unreliable. She wants to convey her own version and will not take anything into account that might contradict its moral. For forty-three years, she has isolated herself and imposed barriers between her "room with the blinds all closed and fastened" (Faulkner 1995, 7) and the outside world. Whenever she refers to someone else's opinion, she does so with the sole purpose of refuting it. The phrase that usually introduces these rare digressions - "they will have told you doubtless" (Faulkner 1995, 134) - is another example of her dualistic worldview, pitting herself against everyone else. Her attitude does not allow for real communication - significantly, she does not even notice that Quentin is not paying attention to her monologue - and thus confines herself to her narrow world. When she has to confront the world outside, she tries to impose her pattern of divine retribution on those around her, namely, Henry and Clytie. But she fails to bring Henry to justice and, unable to come to terms with this failure, dies shortly afterwards.

Rosa tells the story to Quentin Compson, who, in between, also hears it from his father, Jason Richmond Compson. Comparing the two narrators, we find that Mr. Compson's approach is very different from Rosa's. He has not known Sutpen himself, but he can draw from a variety of sources: the elder townspeople's gossip, the story his father, General Compson, heard from Sutpen, the basic line of Rosa's argument as stated by Quentin, and several written documents such as Bon's letter to Judith and the tombstone 
inscriptions. This makes his perspective more comprehensive but at the same time more speculative.

On the one hand, his array of sources, combined with his education and his temporal and emotional distance from the events, permits him to stand outside the events that he narrates. The position he assumes is that of the Olympic narrator who knows (or pretends to know) the intentions, hopes, and fears of all the characters; he is able to assess the collective mind of the townspeople and constantly switches between several perspectives. Conscious of his superior position, he tends to picture others as narrow-minded and limited in their perspective. He does weave the others' versions into his own and considers them at length, which is a step toward plurality and a pronounced contrast to Rosa's dogmatism, but a closer look shows that he does not let the other voices speak freely. His treatment of Bon's letter is paradigmatic of his strategy in dealing with differing voices. He deliberately makes it a part of the story by pointing out its existence to Quentin. He draws heavily from it and makes it the starting point of his lengthy query into Bon's and Henry's psyche. But he only shows the letter to Quentin after he has told his own version of the story. Bon's voice is not allowed to speak freely, but is framed, defined, and restricted by Mr. Compson's authorial power. This pattern pervades his narrative and becomes especially obvious when he turns to Rosa: he does so with the intention of undermining her account of what happened. He demonstrates her unreliability by hinting that her information is incomplete ("Miss Rosa didn't tell you that two of the niggers in the wagon that day were women?" [Faulkner 1995, 61]) and that through his superior analysis he has come to know her even better than she knows herself: "... that triumvirate of which Miss Rosa tried without realizing it to make two" (Faulkner 1995, 64, my emphasis).

Obviously, Mr. Compson wants his son to assume a perspective different from Rosa's, which he regards as highly unreliable and much too narrow. His own motivation is more complex: he wants his first-born to understand and preserve the Southern values and tradition embedded in the story of Thomas Sutpen. While Rosa pursues the short-term goal of persuading Quentin to drive her out to the plantation, Mr. Compson has a long-term objective that requires that Quentin be convinced of the importance of the story and its background. Rosa's account is a monologue: the urgency of her concern does not allow for distraction or discussion. In contrast, Mr. Compson is a leisurely, well-off lawyer and estate owner who spends much time reading stories from the past and can often be seen sitting in his office "all day long with ... dog-eared Horaces and Livys and Catulluses" (Faulkner 1995, 709). When presented with an opportunity to instill a similar thirst for history in his son, he takes his time to indulge in a pleasurable tale. He makes sure that Quentin understands the ramifications of the plot by frequently addressing and involving him ("you see"). Instead of delivering a monologue, he encourages Quentin to draw his own conclusions, for example about the financial sources of the gravestones: 
"But that dont explain the other three," he said. "They must have cost something too."

"Who could have paid for them?" Mr. Compson said. Quentin could feel him looking at him. "Think." (Faulkner 1995, 190)

His efforts to help Quentin understand the story by drawing him into it result in a more dialogic pattern that enriches his tale and contributes to Quentin's understanding of it. But these efforts also result in a highly speculative narrative. Although he has a variety of sources, Mr. Compson's perspective is too narrow to fulfill the expectations he himself has awakened by assuming the position of an Olympic narrator. Quite frequently, there are gaps in his story that he cannot fill, and in order to maintain his superior position, he resorts to conjecture without directly admitting to it. Often, he relates incidents as if he had witnessed them himself, and it is only afterwards that he admits to speculating. When he tells Quentin how Rosa made garments for Judith's wedding, he says:

She got the cloth from her father's store. She could not have got it anywhere else. Your grandmother told me that at that time Miss Rosa actually could not count money ... So she would have to get the material from him. (Faulkner 1995, 77)

Initially we are deceived into believing that Mr. Compson knows where Rosa got the cloth. But in the next sentence he reveals that this is merely conjecture based on someone else's gossip and therefore doubly unreliable. The frequent use of prepositions such as "perhaps", "probably", and "maybe" underlines that his story is often based on his imagination rather than on facts. Thus he unwittingly contributes to the plurality of voices by adding entirely new ones.

These ambiguities, however, do not obfuscate his story - on the contrary, they help him create an exciting plot which Quentin remembers in surprising detail half a year later, in Cambridge. His influence, which is symbolized by the letter at which Quentin keeps staring while drawing his conclusions, is so strong that it even extends onto Quentin's roommate. Shreve McCannon, a medical student from Canada, finds his scientific interest kindled and engages in the task of filling the logical gaps more convincingly. The multitude of imaginative voices and scenes that Mr. Compson set free transcend his own version of the story and create a dialogue that will perpetuate and multiply itself through the voices of the succeeding narrators.

Quentin and Shreve take up the story in their Harvard dormitory room on a cold winter evening, a setting quite different from the hot September day that framed Rosa's and Mr. Compson's narratives in Jefferson. The contrast implies that the students approach the issue not only with a cool mind, but also with a certain distance from Southern prejudices and traditions. Their narrative is open to other perspectives and thus allows for a variety of different voices that sometimes merge to the point that they become virtually indistinguishable. Any attempt to separate Quentin and Shreve's voices 
completely seems futile, but it is possible to outline certain differences between their perspectives as their récit unfolds.

The Harvard section opens up with an outside voice: Mr. Compson's letter that brings the news of Rosa's death. It is read out at the very beginning and allowed to speak freely; no restrictive frame is imposed on it. Thus it does not serve as a proof embedded in a fixed system of logical explanations - as does Bon's letter in Mr. Compson's narrative - but becomes the starting point of a dialogic narrative in which every voice is accepted and treated as potentially enriching. Quentin and Shreve actively contribute to this dialogue by questioning all the explanations they consider, including their own. It is Shreve, a scientist from the North, who encourages Quentin to reconsider the explanations he has heard so far by submitting them to incredulous scrutiny. Quentin soon adopts this method and in turn questions his roommate's conjectures. They are drawn into the story and they tell it together, entering into "some happy marriage of speaking and hearing wherein each before the demand, the requirement, forgave condoned and forgot the faulting of the other" (Faulkner 1995, 316). Their approaches differ slightly and combine to open a variety of new perspectives on the story. The difference between them reflects the difference between the two characters on which their narrative focuses. Quentin has much in common with Henry: both are highly empathetic, accept their limits, value the Southern code of honor, and have a rampant imagination. Shreve, like Bon, is an outsider who regards with an air of amused superiority his mate's seriousness and provinciality, but also assumes the role of the older brother, guiding and protecting the younger. When Shreve offers to cover Quentin with his overcoats in the cold room, he mirrors Bon's care for Henry at Pittsburgh Landing:

He swings the cloak from his shoulders and holds it out.

-No, Henry says.

-Yes. Take it. I'll get my blanket.

Bon puts the cloak about Henry and goes and takes up his tumbled blanket and swings it about his shoulders, and they move aside and sit on a log. (Faulkner 1995, 356)

Moreover, the guiding function of the older "brother" stirs the imagination of the younger. Both Bon and Shreve open up new perspectives to their respective "brother" by initiating him into worlds different from rural Mississippi and by providing an independent role model that allows him to overcome his father's totalizing influence.

Shreve influences Quentin's approach to the Sutpen story in several ways. He broadens Quentin's horizon by sensitizing him to the narrowness of the Southern perspective and, more specifically, helps him see the shortcomings of Mr. Compson's narrative by pointing out the lack of evidence. He offers alternative solutions to some of the main questions that $\mathrm{Mr}$. Compson could not answer and even discovers the pivotal element of the story: the fact that 
Bon is Sutpen's mixed-blood son. Quentin is drawn into the play of conjectures and enriches Shreve's factual conclusions with his imaginative power, making up dramatic stories that are based on these conclusions but transcend them and in turn alter Shreve's view. The reciprocity deepens as the roommates come to a growing understanding of each other (and the characters of their story) by looking at the events from several perspectives. The Christmas scene in which Sutpen reveals the secret of Bon's mistress to Henry, for instance, is described through Henry's eyes as well as through Bon's. Finally, Quentin and Shreve overcome the spatial and temporal distance and the two levels of the plot merge into one: "now it was not two but four of them riding the two horses through the dark over the frozen December ruts of that Christmas Eve: four of them and then just two-CharlesShreve and Quentin-Henry" (Faulkner 1995, 334). Yet another dimension of plurality is opened up, a dimension in which the story and its récit are reintegrated.

\section{Reintegrative Interdiscourse: Dialogicity}

In Quentin and Shreve's récit, Sutpen's sons are allowed to develop an autonomous personality, which doubles the number of voices: now there are four narrators in one and the same narrative. In one way or the other, this process is at work in the entire novel: it is constitutive of the narration. As the novel progresses, the voices of which it is made up multiply and come to interact more and more closely. While this occasionally results in some confusion, on the whole it enriches our understanding of the story. From a Bakhtinian perspective, this is because the novel relies on a dialogic conception of truth: it seeks to convey the story not in a single, unified interpretation but through the inclusion of all its characters' autonomous voices. The following description from Stephen B. Oates' biography gives a sense of Faulkner's dialogic approach to authorship.

When Faulkner finished the Benjy section [of The Sound and the Fury], he wasn't satisfied. Somehow Benjy's view of events needed to be clarified. On inspiration, Faulkner let Quentin, the firstborn son, tell his version in a streamof-consciousness style. But Faulkner still didn't think the story was right. $\mathrm{He}$ tried again, this time switching to the voice and view of Jason. But the story, growing into a fair-sized novel, still wasn't clear. Perplexed, Faulkner tried for a month to clarify matters. Finally, in the last section, he told the story himself, trying as omniscient narrator to fill in the gaps and gather the pieces into a coherent whole. (Oates 1987, 74f.)

Evidently, Faulkner thinks that it is impossible to convey the story adequately from a single perspective. As many of the Compsons as possible must get the opportunity to present their version - not as characters in a unified narrative whole, but as narrators in their own right. Benjy, Quentin, and 
Jason are each allotted a whole section of the novel, and Faulkner only makes his own voice heard to tidy up after them. His version is determined by theirs, not the other way round. These principles apply to Absalom as well. The bulk of the novel is narrated by Rosa, Mr. Compson, Quentin, and Shreve, while Faulkner's voice, the omniscient third-person narrator, merely provides a short introduction and an equally short concluding chapter. Other than that, it is confined to occasional short explanations and "stage directions".

These formal characteristics are indicative of Faulkner's dialogic conception of truth. He believes that the world, and especially the imaginary world of Yoknapatawpha County, is too complex to be represented by a single voice. Consequently, he strives to include a variety of autonomous voices into his novels. Not only does he let several characters tell their version of the story, but he even transforms the potentially synthetic thirdperson narrator into a dialogic instance. As we have seen, Bakhtin regards the narrator as a dialogizing force when he "functions as a compositional substitute for the author's word" (Bakhtin 1984, 190). Faulkner makes use of this possibility and supplements the narrator's discourse with the characters' to make it double-voiced. Take, for example, the narrator's first description of Shreve:

"Yes," Quentin said. He sounds just like father he thought, glancing (his face quiet, reposed, curiously almost sullen) for a moment at Shreve leaning forward into the lamp, his naked torso pink-gleaming and baby-smooth, cherubic, almost hairless, the twin moons of his spectacles glinting against his moonlike rubicund face, smelling (Quentin) the cigar and the wistaria, seeing the fireflies blowing and winking in the September dusk. (Faulkner 1995, 181)

The intricate structure of this passage serves to blur the boundaries between the different voices it contains. At first, the perspective seems clearly to be Quentin's, who holds the subject position not only grammatically, but also in the hierarchical relationships of speaking, thinking, and gazing, in which his father and Shreve are objectified. But as soon as the narrator takes over, Quentin's interpretive authority is undermined and the rhythm of the sentence eludes his control. The well-ordered succession of short observations is abruptly sped up and suddenly we find ourselves in what seems to be a new sentence centered on Shreve. Grammatically speaking, the gerund construction "Shreve leaning forward" deludes us into thinking that a new sentence has begun whose subject is Shreve, while it really introduces the object of the original sentence, that is, it describes what Quentin is glancing at. The narrator thus introduces Shreve as an autonomous voice from the beginning; in fact, he is so successful at elevating him to a near-subject position that at the end of the sentence he has to clarify that it is really Quentin, the grammatical subject, to whom "smelling the cigar ..." refers.

Furthermore, the narrator dialogizes the sentence by indicating that Quentin's thoughts and observations are in turn influenced by other utter- 
ances. Before Quentin even gets the chance to describe Shreve, the narrator turns the tables and inserts a short, precise description of Quentin himself, whose interpretive authority as the gazing subject is decisively undermined once we perceive him as the object who is being gazed at. This instability allows another voice to enter the utterance, a voice whose preference for abundant, repetitive metaphors ("twin moons", "moonlike") and classicist expressions ("torso", "cherubic", "rubicund") we have learned to recognize in the previous chapters. It is the voice of Mr. Compson, Quentin's Horacereading father, whose recent letter has kindled the boys' interest in the story. Judging from its style and diction, the description is more Mr. Compson's than his son's - an impression confirmed by Quentin's lapse into intense, sensual memories of the September evening when he heard his father's version of the story, smelling his cigar and watching the fireflies.

Of course, Quentin is not the only character whose perspective is influenced by other voices. Bakhtin reminds us that every utterance is shaped by previous utterances, although some are more open to dialogue than others. In Absalom, we find that the more distant the narrators are from the Sutpen plot, the more dialogic their narratives become. This is because they have heard previous versions, which find a way into their own. The most dialogic version, then, is Faulkner's: the novel itself. An author holding a dialogic worldview finds himself in a situation much like Quentin's in the passage I have quoted. He appears to be the sole authority in his imaginary world, but the characters turn out to be no mere objects of his gaze but autonomous subjects in their own right. Their voices assert themselves in his narrative and dissolve his interpretive authority: the novel becomes polyphonic.

I have mentioned that polyphony can be defined as the interplay between the formal-linguistic, discursive, and epistemological aspects of dialogicity in literature. We can now describe it more precisely as the confrontation between different autonomous voices on the level of narration. While most of these voices are monologic, their reintegration in dialogue undermines this monologicity and is therefore inherently dialogic. It is important to note that in this context, 'reintegration' means not just the conversation or interaction of characters in the novel. In Zapf's terminology, it refers to the integration in the literary text of 'interdiscursive' elements, that is, of patterns of perception originating in other, more specialized discourses (cf. Link 1984, 157-65). Out of the spectrum of discursive elements operating in a culture, only those which seem in some way typical or exemplary are incorporated into the literary text, where they acquire additional connotations and thus connect the discourses in which they are rooted. To some extent, this applies to monologic texts as well, but it is only in the polyphonic text that the full interdiscursive potential is realized. Here, the characters are no mere showcases of typified traits ascribed to them by the author but autonomous personalities whose complex discursive backgrounds resonate in their speech. Take, for example, Mr. Compson's description of Mr. Coldfield's death and legacy: 
The store was just a shell, the deserted building vacated even by rats and containing nothing, not even goodwill since he had irrevocably estranged himself from neighbors, town, and embattled land, all three by his behavior. Even the two negresses were gone now - whom he had freed as soon as he came into possession of them ... in return for which they had been among the first Jefferson negroes to desert and follow the Yankee troops. So when he died, he had nothing, not only saved but kept. Doubtless the only pleasure which he ever had was not in the meager spartan hoard which he had accumulated before his path crossed that of his future son-in-law - not in the money but in its representation of a balance in whatever spiritual countinghouse he believed would some day pay his sight drafts on self-denial and fortitude. (Faulkner 1995, 84)

The very expressions that Mr. Compson uses have a strong interdiscursive tendency. Most notably, he relies on classicist expressions ("Spartan") and on metaphors, many of which are meant to help Quentin understand the story. But Mr. Compson's elaborate diction somewhat undermines this didactic purpose. While it might certainly be helpful, for example, to explain Mr. Coldfield's Calvinistic worldview in financial terms, complicated constructions such as "sight drafts on self-denial and fortitude" do not make things easier for Quentin. It is this pervasive tension between different, often contradictory forces in Mr. Compson's narrative that bears witness to his complex discursive background. His comment on the behavior of $\mathrm{Mr}$. Coldfield's female slaves, for instance, indicates both a strong sense of justice derived from a humanistic worldview and a remarkable insensitivity to the inhuman treatment of black slaves. Similarly, he empathizes with $\mathrm{Mr}$. Coldfield's spirituality but does so with an attitude of superiority verging on open ridicule. His values derive from the contradictory ideals of the South, which include communality, white supremacy, allegiance to the "embattled land", unerring respect for the heroes of the past (such as Sutpen), and a certain nostalgic fatalism.

In the polyphonic novel, the characters' autonomy enhances the variety and depth of interdiscursive reintegration. As the novel progresses, we find more divergent utterances and thus an increasingly complex understanding of the characters and the story they are telling. This complexity is an enormous challenge to us, the readers, but it is also a means of emancipation. We are forced to abandon our attempts at synthesizing all the narratives into a unified picture; instead, we are drawn into the polyphony of voices and are given the opportunity to interact dialogically. The novel's interdiscursive structure makes it dialogic on a linguistic level and at the same time promotes a dialogic worldview. And this is how literature assumes a cultural function: it regenerates its culture by disseminating a more viable, dialogic epistemology. Faulkner, who was confronted with conflicting, sometimes irreconcilable voices and ideas all his life, was more sensitive than most other writers to the regenerative possibilities of literature and brought them to fruition in his most dialogic novel, Absalom, Absalom! 


\section{Works Cited}

Arendt, Hannah. 1950. “The Imperialist Character.” Review of Politics 12: $303-$ 20.

Bakhtin, Mikhail. 1984. Problems of Dostoevsky's Poetics. Ed. and trans. Caryl Emerson. Manchester: Manchester UP.

Bandry, Michel. 1984. "Et Sutpen créa Sutpen...” From Rags to Riches: Le mythe $d u$ self-made man. Ed. Serge Ricard. Aix-en-Provence: Imprimerie de l'Université de Provence. 83-94.

Cullick, Jonathan S. 1996. "'I had a design': Sutpen as Narrator in Absalom, Absalom!” Southern Literary Journal 28.2: 48-58.

Emerson, Ralph Waldo. 1985. "Self-Reliance." Selected Essays. New York: Penguin. $175-203$.

Faulkner, William. 1995. Absalom, Absalom! London: Vintage.

-. 1967a. "Address upon Receiving the Nobel Prize for Literature." The Portable Faulkner. Ed. Malcolm Cowley. Rev. ed. New York: Viking, 723-24.

—. 1967b. "The Compsons." The Portable Faulkner. Ed. Malcolm Cowley. 70421.

—. 1965. "On Fear: Deep South in Labor: Mississippi." Essays, Speeches and Public Letters. Ed. James B. Meriwether. New York: Random House. 92-106.

Genette, Gérard. 1980. Narrative Discourse: An Essay in Method. Trans. Jane E. Lewin. Ithaca: Cornell UP.

Kartiganer, Donald M. 1964. "The Role of Myth in Absalom, Absalom!" Modern Fiction Studies 9.4 : 357-69.

Link, Jürgen. 1984. "Interdiscourse, Literature, and Collective Symbols: Theses Towards a Theory of Discourse and Literature." Enclitic 8: 157-65.

Morson, Gary Saul and Caryl Emerson. 1990. Mikhail Bakhtin: Creation of a Prosaics. Stanford: Stanford UP.

Oates, Stephen B. 1987. William Faulkner: The Man and the Artist. New York: Harper \& Row.

Zapf, Hubert. 2002. Literatur als kulturelle Ökologie: Zur kulturellen Funktion imaginativer Texte an Beispielen des amerikanischen Romans. Tübingen: Niemeyer. 